\title{
ABCA1 deficiency and cellular cholesterol accumulation increases islet amyloidogenesis in mice
}

\author{
Nadeeja Wijesekara $^{1}$ - Achint Kaur ${ }^{1}$ - Clara Westwell-Roper ${ }^{2}$. Dominika Nackiewicz ${ }^{3}$. \\ Galina Soukhatcheva $^{2}$ - Michael R. Hayden ${ }^{1}$ - C. Bruce Verchere ${ }^{2,3}$
}

Received: 6 August 2015 / Accepted: 19 January 2016/Published online: 12 March 2016

(C) Springer-Verlag Berlin Heidelberg 2016

\begin{abstract}
Aims/hypothesis Islet amyloid, a pathological feature of type 2 diabetes, forms from the aggregation of islet amyloid polypeptide (IAPP), a beta cell peptide that is produced and co-secreted with insulin. Cholesterol regulates amyloid- $\beta$ processing, deposition and clearance, promoting amyloidogenesis in the brain. ATP-binding cassette transporter 1 (ABCA1) is a cholesterol efflux transporter that when absent increases and when overexpressed reduces brain amyloid- $\beta$ deposition in mouse models of Alzheimer's disease. We examined whether alterations in ABCA1 expression and islet cholesterol content could also modulate islet amyloidogenesis.

Methods Thioflavin S staining for amyloid was performed in islets isolated from mice with beta cell expression of human IAPP $\left(\mathrm{h} I A P P^{\mathrm{Tg} / \mathrm{o}}\right)$ and cultured for 8 days following cholesterol loading, microRNA-33 overexpression (to reduce ABCA1 expression) or palmitate treatment in the presence or absence of $\mathrm{ABCA} 1$ overexpression or mevastatin treatment (to reduce cholesterol synthesis). $\mathrm{h} I A P P^{\mathrm{Tg} / \mathrm{o}}$ mice were
\end{abstract}

Electronic supplementary material The online version of this article (doi:10.1007/s00125-016-3907-6) contains peer-reviewed but unedited supplementary material, which is available to authorised users.

C. Bruce Verchere

bverchere@cfri.ca

1 Department of Medical Genetics, Centre for Molecular Medicine and Therapeutics, Child \& Family Research Institute, University of British Columbia, Vancouver, BC, Canada

2 Department of Pathology \& Laboratory Medicine, Child \& Family Research Institute, University of British Columbia, 950 West 28th Avenue, Vancouver, BC V5Z 4H4, Canada

3 Department of Surgery, Child \& Family Research Institute, University of British Columbia, Vancouver, BC, Canada crossed with beta cell-specific Abcal-knockout mice $\left(\mathrm{h} I A P P^{\mathrm{Tg} / \mathrm{o}} A b c a 1^{\beta \mathrm{KO}}\right)$ and glucose tolerance and amyloid formation were assessed.

Results Cholesterol loading and microRNA-33-induced reduction in islet ABCA1 expression increased Thioflavin S-positive amyloid in $\mathrm{h} I A P P^{\mathrm{Tg} / \mathrm{o}}$ islets. Palmitate treatment also increased amyloid formation and this was reduced by both ABCA1 overexpression and mevastatin treatment. $\mathrm{h} I A P P^{\mathrm{Tg} / \mathrm{o}} A b c a 1^{\beta \mathrm{KO}}$ mice had increased islet cholesterol, accompanied by fasting hyperglycaemia, glucose intolerance, impaired in vivo insulin secretion and an increased islet proinsulin:insulin ratio. Amyloid area was increased in cultured $\mathrm{h} I A P P^{\mathrm{Tg} / \mathrm{o}} A b c a 1^{\beta \mathrm{KKO}}$ islets compared with $\mathrm{h} I A P P^{\mathrm{Tg} / \mathrm{o}}$ controls.

Conclusions/interpretation These data suggest that elevations in islet cholesterol may lead to increases in IAPP aggregation and islet amyloid formation, further worsening beta cell function and glucose homeostasis.

Keywords ABCA1 · Cholesterol $\cdot$ IAPP $\cdot$ Islet amyloid

$\begin{array}{ll}\text { Abbreviations } \\ \text { ABCA1 } & \text { ATP-binding cassette transporter 1 } \\ \text { AD } & \text { Alzheimer's disease } \\ \text { hIAPP } & \text { Human IAPP } \\ \text { IAPP } & \text { Islet amyloid polypeptide } \\ \text { miR-33 } & \text { MicroRNA-33 }\end{array}$

\section{Introduction}

Glucolipotoxicity, endoplasmic reticulum stress, inflammation, accumulation of islet cholesterol and islet amyloid have all been implicated in the islet dysfunction associated with 
type 2 diabetes [1]. Islet amyloid, a pathological feature of some type 2 diabetes patients, forms from the aggregation of islet amyloid polypeptide (IAPP), a 37-amino-acid beta cell peptide that is produced and co-secreted with insulin. Aggregated forms of human IAPP (hIAPP) induce beta cell death and trigger islet inflammation [2]. Whereas hIAPP spontaneously assembles into amyloid fibrils having primarily a $\beta$-sheet conformation, three $\beta$-sheet-breaking proline residues prevent aggregation of the rodent peptide. Therefore, several transgenic mouse models expressing hIAPP driven by the rat insulin 2 promoter have been developed [3]. In these models, islet amyloid associated with reduced beta cell mass or function is observed, usually requiring some beta cell stress such as high-fat diet.

Alzheimer's disease (AD) is a neurodegenerative disorder characterised by accumulation of amyloid plaques. Accumulation of lipoprotein and cholesterol increases the risk of $\mathrm{AD}$ and some cholesterol-lowering drugs reduce the risk of dementia [4]. Cholesterol has been shown to regulate amyloid- $\beta$ processing, deposition and clearance and promote amyloidogenesis in the brain. Studies suggest that genetic variability of the cholesterol efflux transporter, ATP-binding cassette transporter 1 (ABCA1), influences the development and risk of AD [5]. Deletion of Abcal has been shown to increase, while overexpression of $A b c a 1$ reduces, amyloid- $\beta$ deposition in $\mathrm{AD}$ mouse brains.

We previously reported that deletion of beta cell Abcal leads to islet cholesterol accumulation, beta cell dysfunction and impaired glucose tolerance [6]. To determine whether beta cell deletion of $A b c a l$ and islet cholesterol accumulation would enhance amyloid formation in the islet as it does in the brain, we studied mice with beta cell expression of hIAPP but lacking ABCA1.

\section{Methods}

Mice Mice expressing $\mathrm{h} I A P P$ under the rat insulin 2 promoter $\left(\mathrm{h} / A P P^{\mathrm{Tg} / \mathrm{o}}\right)[\mathrm{FVB} / \mathrm{N}-\mathrm{Tg}($ Ins 2-IAPP)RHFSoel/J, The Jackson Laboratory, Bar Harbor ME USA), RIP-Cre ${ }^{\mathrm{Tg} / \mathrm{o}}$ [B6.Cg$\operatorname{Tg}($ Ins 2-cre) $25 \mathrm{Mgn} / \mathrm{J}$, The Jackson Laboratory, Bar Harbor ME USA], floxed Abcal (Abcal $\left.{ }^{\text {loxp/loxp }}\right)$ mice and beta cellspecific $A b c a l$-knockout $\left(A b c a 1^{\beta K O}\right)$ mice have been previously described [6-8]. To generate mice with specific expression of beta cell hIAPP, but lacking beta cell ABCA1, $\mathrm{h} I A P P^{\mathrm{Tg} / \mathrm{o}}$ mice were crossed with $A b c a 1^{\text {loxp/loxp }}$ mice to generate $\mathrm{h} I A P P^{\mathrm{Tg} / \mathrm{o}} A b c a 1^{\mathrm{loxp} /-}$ mice, which were then crossed together to generate $\mathrm{h} I A P P^{\mathrm{Tg} / \mathrm{o}} A b c a 1^{\text {loxp/loxp }}$. These mice were bred with RIP-Cre ${ }^{\mathrm{Tg} / \mathrm{o}} \mathrm{Abca} 1^{\text {loxp/loxp }}$ mice [6] to create $\mathrm{h} I A P P^{\mathrm{Tg} / \mathrm{o}} A b c a 1^{\beta \mathrm{KO}}$ mice. Male mice at 4 months of age were used for all studies. All animals had free access to standard mouse chow and water, and were housed in a temperaturecontrolled facility with a $12 \mathrm{~h}$ light/dark cycle. All experiments were approved by the Animal Care Committee at the University of British Columbia.

In vivo and islet studies Islets were isolated from 4-month old male mice and were subjected to cholesterol loading, microRNA-33a (miR-33a) overexpression and palmitate treatment in $22 \mathrm{mmol} / \mathrm{l}$ glucose followed by Thioflavin $\mathrm{S}$ staining as described in ESM Methods. Cultured (following cholesterol loading and $m i R-33$ and Abcal overexpression) and freshly isolated $\left(h I A P P^{T g / o} A b c a l^{\beta K O}\right)$ islets were subjected to western blotting and cholesterol measurement (See ESM Methods for more details). Glucose tolerance tests were carried out in 4-month-old male mice and plasma insulin and proinsulin were measured using ELISA kits from ALPCO Diagnostics (Salem, NH USA) as described in ESM Methods. Samples were not randomised and were not blind to group assignment and outcome assessment.

Statistical analysis Data are expressed as mean \pm SEM. Significance was determined using Student's $t$ test or one- or two-way analysis of variance. A $p$ value $<0.05$ was considered statistically significant. No data, samples or animals were excluded from reporting.

\section{Results}

To determine whether elevated islet cholesterol would enhance islet amyloid formation, $\mathrm{h} I A P P^{\mathrm{Tg} / \mathrm{o}}$ islets were cultured in cholesterol $(2 \mathrm{mmol} / \mathrm{l})$ or transduced with recombinant adenovirus expressing miR-33a, a negative regulator of ABCA1 expression that is known to increase islet cholesterol in an ABCA1-dependent manner [9]. Addition of cholesterol to the culture media led to significantly elevated total islet cholesterol levels following 8 days' culture (ESM Fig. 1a), and this was associated with a twofold increase in amyloid area as assessed by Thioflavin S staining (Fig. 1a). miR-33a expression reduced islet ABCA1 expression (ESM Fig. 1b) and increased amyloid formation by 1.67 -fold (Fig. 1b) in cultured $\mathrm{h} I A P P^{\mathrm{Tg} / \mathrm{o}}$ islets. As expected, cholesterol loading had no effect on Thioflavin S-positive amyloid formation in mice not expressing the amyloidogenic $\mathrm{h} I A P P$ transgene (ESM Fig. 1e).

Palmitate treatment has been associated with elevated beta cell cholesterol content and IAPP aggregation in vitro $[10,11]$. In keeping with these reports, culture of $\mathrm{h} I A P P^{\mathrm{Tg} / \mathrm{o}}$ islets in the presence of $0.1 \mathrm{mmol} / 1$ palmitate led to a 2.74 -fold increase in Thioflavin S-positive area (Fig. 1c). Adenoviral overexpression of Abcal (ESM Fig. 1b) and treatment with mevastatin, both of which lower islet cholesterol levels [9], led to marked reduction in palmitate-induced amyloid formation (Fig. 1c).

To determine whether ABCA1 deficiency in vivo would exacerbate amyloid formation, we generated $\mathrm{h} I A P P^{\mathrm{Tg} / \mathrm{o}}$ mice 

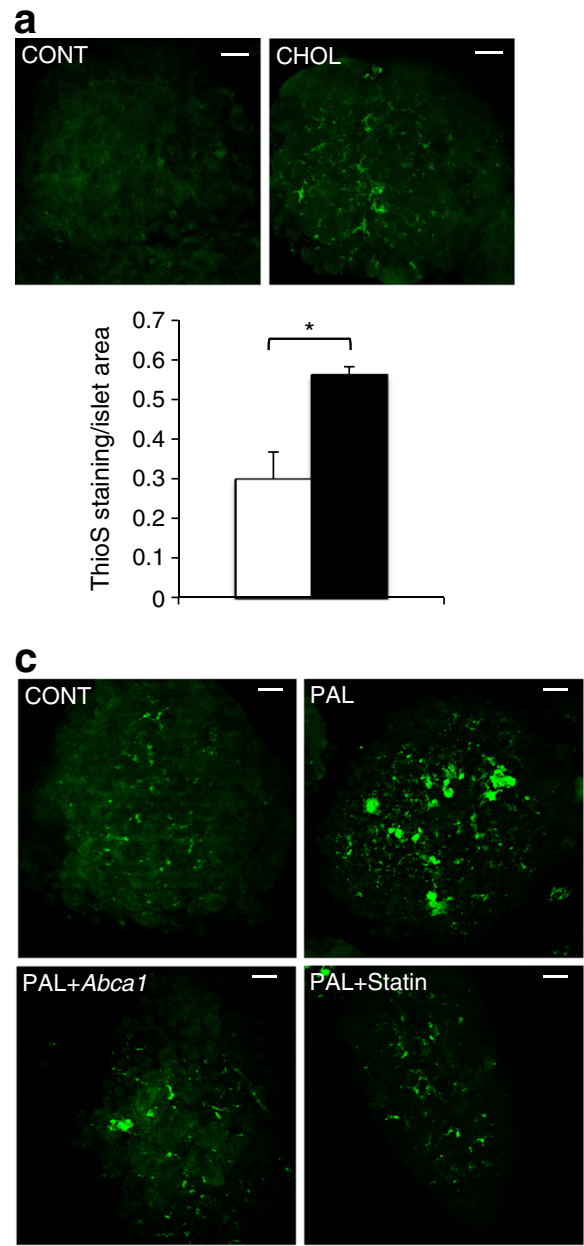

Fig. 1 Intracellular cholesterol modulation affects amyloid accumulation in $\mathrm{h} I A P P^{\mathrm{Tg} / \mathrm{o}}$ islets. (a) Amyloid area determined by Thioflavin S (ThioS) staining in islets cultured in $22 \mathrm{mmol} / \mathrm{l}$ glucose with cholesterol loading. $\mathrm{h} I A P P^{\mathrm{Tg} / \mathrm{o}}$ islets were cultured in the absence (CONT, white bar) or presence of $2 \mathrm{mmol} / \mathrm{l}$ cholesterol (CHOL, black bar) in culture media for 8 days. ${ }^{*} p<0.05$ (paired Student's $t$ test); $n=3$. (b) Amyloid area determined by ThioS staining in islets cultured in $22 \mathrm{mmol} / 1$ glucose with miR33a overexpression. $\mathrm{h} I A P P^{\mathrm{Tg} / \mathrm{o}}$ islets were transduced with 100 multiplicity of infection (MOI) empty vector control (Adv-CONT, white bar) or miR-33a adenovirus (Adv-miR33, black bar) for $24 \mathrm{~h}$ and further cultured

deficient in beta cell ABCA1 ( $\left.\mathrm{h} I A P P^{\mathrm{Tg} / \mathrm{o}} A b c a 1^{\beta \mathrm{KO}}\right)$. These mice as expected had reduced islet ABCA1 expression (ESM Fig. 1c) as well as increased islet cholesterol accumulation (ESM Fig. 1d). Interestingly, at 4 months of age, male $\mathrm{h} I A P P^{\mathrm{Tg} / \mathrm{o}} A b c a 1^{\beta \mathrm{KO}}$ mice had fasting hyperglycaemia, whereas all three control groups, including $\mathrm{h} I A P P^{\mathrm{Tg} / \mathrm{o}}$ and $A b c a 1^{\beta K O}$ remained normoglycaemic (Fig. 2a). As expected, both $A b c a 1^{\beta \mathrm{KO}}$ and $\mathrm{h} I A P P^{\mathrm{Tg} / \mathrm{o}}$ transgenic mice had mild impairment in glucose tolerance compared with nontransgenic controls, whereas the combination of beta cell hIAPP expression and ABCA1 deficiency led to more marked glucose intolerance (Fig. 2b). $\mathrm{h} I A P P^{\mathrm{Tg} / \mathrm{o}} A b c a 1^{\beta \mathrm{KO}}$ mice also showed impaired in vivo glucose-stimulated insulin secretion when compared with $\mathrm{h} I A P P^{\mathrm{Tg} / \mathrm{o}}$ mice (Fig. 2c). Moreover,
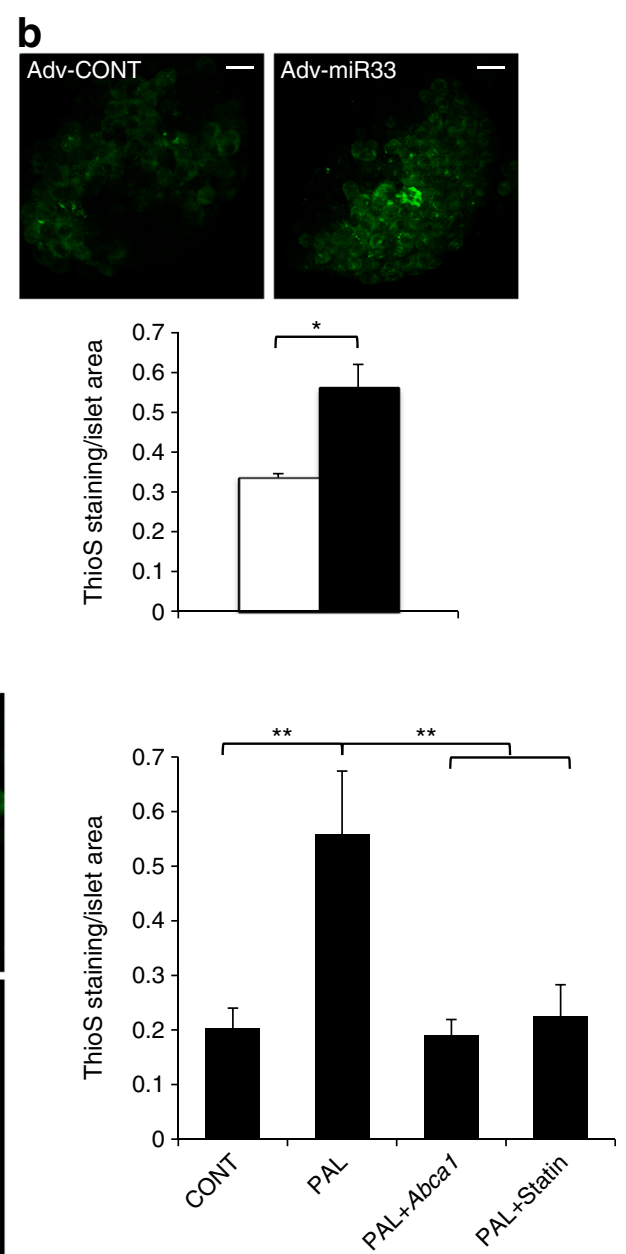

for 7 days. ${ }^{*} p<0.05$ (paired Student's $t$ test); $n=3$. (c) Amyloid area determined by ThioS staining in islets cultured in $22 \mathrm{mmol} / 1$ glucose with $0.1 \mathrm{mmol} / \mathrm{l}$ palmitate. $\mathrm{h} / A P P^{\mathrm{Tg} / \mathrm{o}}$ islets were treated with vehicle (CONT) or $0.1 \mathrm{mmol} / 1$ palmitate (PAL) in $0.5 \%$ BSA. Following $48 \mathrm{~h}$ culture, islets were either transduced with $A b c a l$ adenovirus (100 MOI) for $24 \mathrm{~h}$ followed by a further 5 days' culture in the presence of palmitate $(\mathrm{PAL}+A b c a 1)$ or were treated with $10 \mu \mathrm{mol} / \mathrm{l}$ mevastatin added to the culture media from day 3 to day 8 in the presence of palmitate (PAL+ Statin). $* * p<0.01$ (one-way ANOVA with Tukey's post hoc test); $n=3$. Scale bar, $20 \mu \mathrm{m}$

$\mathrm{h} I A P P^{\mathrm{Tg} / \mathrm{o}} A b c a 1^{\beta \mathrm{KKO}}$ mice had significantly elevated circulating proinsulin:insulin ratios (Fig. 2d), further indicative of beta cell dysfunction. These data suggest that expression of the $\mathrm{h} I A P P$ transgene exacerbates the glucose intolerance and beta cell dysfunction of beta cell ABCA1 deficiency alone. To determine whether lack of ABCA1 in beta cells promotes amyloid formation, we cultured islets isolated from $\mathrm{h} I A P P^{\mathrm{Tg} / \mathrm{o}} A b c a 1^{\beta K O}$ and $\mathrm{h} I A P P^{\mathrm{Tg} / \mathrm{o}}$ mice for 8 days. $\mathrm{h} I A P P^{\mathrm{Tg} / \mathrm{o}} A b c a 1^{\beta \mathrm{KKO}}$ islets had an amyloid area twofold greater than that of islets from $\mathrm{h} I A P P^{\mathrm{Tg} / \mathrm{o}}$ mice, as determined by Thioflavin $\mathrm{S}$ staining (Fig. 2e). However, islet amyloid could not be detected by Thioflavin S staining in pancreatic sections from 4-month-old mice, likely due to the limitations of Thioflavin $\mathrm{S}$ in detecting smaller aggregates. 
Fig. 2 Beta cell ABCA1deficiency exacerbates glucose intolerance in $\mathrm{h} I A P P^{\mathrm{Tg} / \mathrm{o}}$ mice. (a) Fasting blood glucose and (b) glucose tolerance test with inset showing AUC $(n=6-8)$ following $4 \mathrm{~h}$ fast in 4-month-old male non-transgenic (white bars and broken line), $A b c a 1^{\beta K O}$ (light grey bars and line), $\mathrm{h} I A P P^{\mathrm{Tg} / \mathrm{o}}$ (dark grey bars and line) and $\mathrm{h} I A P P^{\mathrm{Tg} / \mathrm{o}} A b c a 1^{\beta \mathrm{KO}}$ (black bars and line) mice $\left({ }^{*} p<0.05\right.$, ${ }^{* *} p<0.01$ and $* * * p<0.001$ vs non-transgenic mice [one-way ANOVA with Tukey's post hoc test]). (c) Insulin secretion during glucose tolerance test $(n=6)$ (white bars, 0 min; black bars, $15 \mathrm{~min}$ ) and (d) plasma proinsulin:insulin ratio $(n=6)$ (white bars, $\mathrm{h} / A P P^{\mathrm{Tg} / \mathrm{o}}$; black bars: $\mathrm{h} I A P P^{\mathrm{Tg} / \mathrm{o}} A b c a 1^{\beta \mathrm{KO}}$ ) from $\mathrm{h} I A P P^{\mathrm{Tg} / \mathrm{o}}$ and $\mathrm{h} I A P P^{\mathrm{Tg} /}$

${ }^{\circ} A b c a 1^{\beta K O}$ mice. (e) Thioflavin $\mathrm{S}$ (ThioS) staining in 8 day cultured islets $(n=4)$ from $\mathrm{h} I A P P^{\mathrm{Tg} / \mathrm{o}}$ (white bars) and $\mathrm{h} I A P P^{\mathrm{Tg} / \mathrm{o}} A b c a 1^{\beta \mathrm{KO}}$ (black bars) mice $\left({ }^{*} p<0.05\right.$ and ${ }^{* *} p<0.01$, unpaired Student's $t$ test). Scale bar, $20 \mu \mathrm{m}$
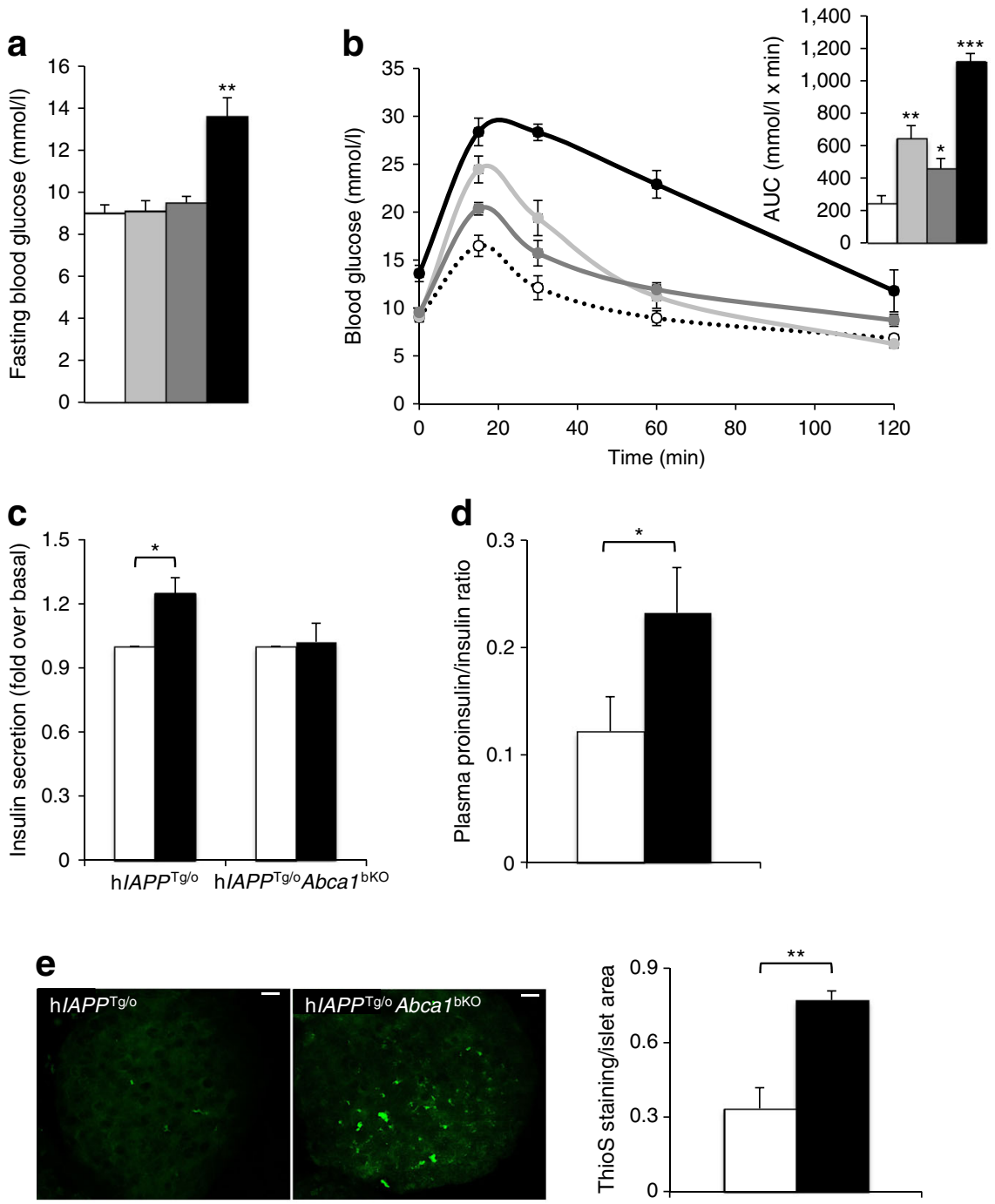

\section{Discussion}

$\mathrm{ABCA} 1$ is a key molecule regulating cholesterol metabolism, controlling the rate-limiting step in HDL biogenesis by effluxing cellular cholesterol and phospholipids to apolipoprotein acceptors [12]. In the absence of beta cell ABCA1, cholesterol accumulates in islets, impairing beta cell function [6]. Changes in cholesterol levels or regulators of cholesterol homeostasis are associated with a number of amyloid diseases [13]. Here we examined whether alterations in ABCA1 expression and islet cholesterol levels would affect IAPP amyloidogenesis, beta cell function and glucose homeostasis. We observed a striking effect of islet ABCA1 deficiency and cholesterol levels on amyloid formation.

Both direct cholesterol loading and a reduction in ABCA1 expression was associated with increased islet cholesterol levels leading to a significant increase in islet amyloid deposition. Conversely, reduction in cholesterol synthesis via mevastatin treatment or Abcal overexpression significantly reduced amyloid load. Therefore, as with other amyloidogenic proteins, cholesterol appears to play a significant role in regulating IAPP aggregation. In keeping with this idea, IAPP-derived amyloid fibrils were reported to occur in cholesterol-rich plasma membrane domains and depletion of plasma membrane cholesterol reduced IAPP oligomer internalisation in human islet cells but led to its extracellular accumulation as amyloid [14].

Glucose intolerance in mice expressing amyloidogenic hIAPP and lacking beta cell $\mathrm{ABCA1}\left(\mathrm{h} I A P P^{\mathrm{Tg} / \mathrm{o}} A b c a 1^{\beta \mathrm{KO}}\right.$ mice) was more severe than in $\mathrm{h} I A P P^{\mathrm{Tg} / \mathrm{o}}$ or $A b c a 1^{\beta \mathrm{KKO}}$ mice, and islets from $\mathrm{h} L A P P^{\mathrm{Tg} / \mathrm{o}} A b c a 1^{\beta K O}$ mice had increased amyloid formation. These data raise the possibility that cholesterol accumulation may exacerbate IAPP aggregation and subsequently beta cell dysfunction. The mechanism by which ABCA1 deficiency and increased cholesterol may affect IAPP aggregation remains unknown but may be related to beta cell defects induced by excess cholesterol, including an insulin granule exocytotic defect, increased islet inflammation, disruption in membrane microdomain organisation and impaired prohormone processing $[8,15]$. 
In summary, we show that modulation of cholesterol levels lead to alterations in islet amyloidogenesis similar to other amyloid diseases. Therapeutics targeting ABCA1 expression or activity and cholesterol lowering may therefore have implications not only in type 2 diabetes but also in other amyloid diseases.

Acknowledgements Some of the data were presented as an abstract at American Diabetes Association 73rd Scientific Session, Chicago, IL, USA, June 2013.

Funding NW is supported by post-doctoral fellowships from the Canadian Institutes of Health Research and Michael Smith Foundation of Health Research. DN is supported by a CIHR-Vanier Canada Graduate Scholarship. MRH is a University Killam Professor and holds a Canada Research Chair in Human Genetics. CBV is supported by the Irving K. Barber Chair in Diabetes Research and an investigator Award from the Child \& Family Research Institute. This work was supported by grants from the Canadian Institutes of Health Research to MRH (MOP-84437) and CBV (MOP-14682).

Contribution statement NW designed the experiments, acquired, analysed and interpreted the data and drafted the manuscript. AK, CW-R, DN and GS contributed to the acquisition and interpretation of the data. CBV and MRH provided a substantial contribution to the conception of the study and interpretation of the data. All authors revised and approved the final manuscript. CBV is the guarantor of this work.

Duality of interest The authors declare that there is no conflict of interest associated with this manuscript.

\section{References}

1. Montane J, Klimek-Abercrombie A, Potter KJ, Westwell-Roper C, Verchere CB (2012) Metabolic stress, IAPP and islet amyloid. Diabetes Obes Metab 14:68-77

2. Westwell-Roper CY, Chehroudi CA, Denroche HC, Courtade JA, Ehses JA, Verchere CB (2015) IL-1 mediates amyloid-associated islet dysfunction and inflammation in human islet amyloid polypeptide transgenic mice. Diabetologia 58:575-585

3. Matveyenko AV, Butler PC (2006) Islet amyloid polypeptide (IAPP) transgenic rodents as models for type 2 diabetes. ILAR J 47:225-233

4. Grösgen S, Grimm MO, Friess P, Hartmann T (2010) Role of amyloid beta in lipid homeostasis. BiochIm Biophys Acta 1801:966974

5. Koldamova R, Fitz NF, Lefterov I (2010) The role of ATP-binding cassette transporter A1 in Alzheimer's disease and neurodegeneration. Biochim Biophys Acta 1801:824-830

6. Brunham LR, Kruit JK, Pape TD et al (2007) Beta-cell ABCA1 influences insulin secretion, glucose homeostasis and response to thiazolidinedione treatment. Nat Med 13:340-347

7. Janson J, Soeller WC, Roche PC et al (1996) Spontaneous diabetes mellitus in transgenic mice expressing human islet amyloid polypeptide. Proc Natl Acad Sci U S A 93:7283-7288

8. Kruit JK, Wijesekara N, Fox JE et al (2011) Islet cholesterol accumulation due to loss of ABCA1 leads to impaired exocytosis of insulin granules. Diabetes 60:3186-3196

9. Wijesekara N, Zhang LH, Kang MH et al (2012) miR-33a modulates ABCA1 expression, cholesterol accumulation, and insulin secretion in pancreatic islets. Diabetes 61:653-658

10. El-Assaad W, Joly E, Barbeau A et al (2010) Glucolipotoxicity alters lipid partitioning and causes mitochondrial dysfunction, cholesterol and ceramide deposition and reactive oxygen species production in INS832/13 b cells. Endocrinology 151:3061-3073

11. Ma Z, Westermark GT (2002) Effects of free fatty acid on polymerization of islet amyloid polypeptide (IAPP) in vitro and on amyloid fibril formation in cultivated isolated islets of transgenic mice overexpressing human IAPP. Mol Med 8:863-868

12. Lee JY, Parks JS (2005) ATP-binding cassette transporter AI and its role in HDL formation. Curr Opin Lipidol 16:19-25

13. Liu JP, Tang Y, Zhou S, Toh BH, McLean C, Li H (2010) Cholesterol involvement in the pathogenesis of neurodegenerative diseases. Mol Cell Neurosci 43:33-42

14. Trikha S, Jeremic AM (2011) Clustering and internalization of toxic amylin oligomers in pancreatic cells require plasma membrane cholesterol. J Biol Chem 286:36086-36097

15. Kruit JK, Wijesekara N, Westwell-Roper C et al (2012) Loss of both $\mathrm{ABCA} 1$ and $\mathrm{ABCG} 1$ results in increased disturbances in islet sterol homeostasis, inflammation, and impaired $\beta$-cell function. Diabetes 61:659-664 